\title{
Emilio Prados: las dos versiones de Jardín cerrado
}

\author{
Antonio Carreira \\ Centro para la Edición de los Clásicos Españoles
}

Título: Emilio Prados: las dos versiones de Jardin cerrado.

Resumen: Examen de algunos poemas de Jardin cerrado (1946), que en su segunda edición (1960) presentan variantes sustanciales.

Palabras clave: Emilio Prados, Jardin cerrado, versiones redaccionales.

Fecha de recepción: 27/1/2014.

Fecha de aceptación: 18/3/2014.
Title: Emilio Prados: the Two Versions of Jardin cerrado.

Abstract: Analysis of several poems of Jardin cerrado (1946), which in the 2 nd edition of that book (1960) appear with substantial changes.

Key words: Emilio Prados, Jardín cerrado, Redactional versions.

Date of Receipt: 27/1/2014.

Date of Approval: 18/3/2014.

El poeta Emilio Prados es uno de los mitos menores de la llamada generación del 27, mito más en cuanto persona que en cuanto poeta, porque ahí casi todo el mundo hace la venia y sigue su camino. No es este el momento adecuado para analizar el fenómeno. Sí para recordar que Prados fue poeta full time, incluso cuando era impresor en Málaga o corregía pruebas en México. No practicó la docencia, ni acabó carrera alguna, ni recibió apenas más ingresos que los procedentes de su familia antes de la guerra, y de su hermano Miguel, psiquiatra en Canadá, después de ella. Eso interesa tenerlo presente para comprender que Prados creó una obra poética de dimensiones considerables, cuya mayor parte publicó en forma de libro, y a la que no cesó de dar vueltas y hacer enmiendas. Prueba 
de ello son las 20 cajas de papeles póstumos que, bien inventariados por Blanco Aguinaga, nos sirvieron a él y a quien esto escribe para publicar una versión razonable de sus Poesias completas en 1975-76, y de nuevo, con estructura más rigurosa, en 1999, año del centenario.

Siempre se ha dicho que Jardín cerrado (México, DF: Cuadernos Americanos, 1946; prólogo de Juan Larrea) es el libro central de Prados, aquel en que encuentra su voz definitiva. El propio poeta debió de creerlo así, puesto que de él publicó una selección amplia en 1953, titulada Dormido en la yerba; en la Antología de 1954 dedica solo a ese libro casi 100 páginas, y, en la misma colección de Losada, publicó una segunda edición completa en 1960, dos ańos antes de su muerte, indicio de que lo seguía considerando válido cuando su estética había variado de rumbo; más válido en sí mismo que la esotérica interpretación de Larrea en el prólogo ahora eliminado. En otro lugar tratamos de los cambios introducidos en los poemas de Dormido en la yerba, y en el texto de Jardín cerrado (= JC) que figura en las Poesías completas de 1999 (= PC) dimos las variantes de versiones impresas anteriores o posteriores. Versiones impresas, no manuscritas, ya que estas no se destinaban al público, y solo tendrían un valor en la llamada crítica genética, no en una edición que trata de representar con exactitud la obra que el autor quiso poner en manos de sus lectores en un determinado momento. Entre eso y los papeles que quedan para uso personal hay una frontera que a veces se cruza con demasiada ligereza; a nuestro juicio, la voluntad del autor es un criterio seguro para no incurrir en el error filológico de conceder igual representatividad a todo lo salido de su pluma. Sin embargo, puede no ser tan seguro en cuanto a la fijación de la obra publicada, que el filólogo ha de ver siempre dentro de su cronología.

La versión de $J C$ que reprodujimos en las $P C$ es la de 1946, pues esa primera edición, cuidada por el propio poeta, es lógicamente la más próxima y fiel al ideario de Prados durante su génesis. Aparte de ello, sus 419 páginas de buen formato constituyen un libro singular también en su aspecto visual y material: los poemas comienzan siempre en página nueva, alterna la numeración romana con la árabe en las subdivisiones, los blancos son generosos, las versales, versalitas, redondas y cursivas intentan establecer una jerarquía en títulos y lemas, los márgenes, sangrados, negritas iniciales y otros detalles indican a las claras que el poeta ha 
echado el resto, y que la editorial, regentada por Juan Larrea, no escatimó esfuerzos al buscar la presentación más digna. Prados, editor e impresor desde su mocedad, hubo de quedar satisfecho, o al menos, hasta donde alcanzamos, nunca dijo lo contrario.

Entre las variantes registradas en la edición de $P C$, nos fijaremos en tres casos. Sea el primero una sección del poema "Bajo la alameda", sexto de la primera parte, "Nostalgias y sueños", del libro primero de Jardín cerrado:

Con temores voy

pero voy.

Y esto que marcha

conmigo;

y esto que va

5

tras de mí,

y esta sombra

a la que sigo

con temores,

¿a dónde va?:

¿dónde voy?...

-Con temores.

(JC, 1946, pp. 42-43; PC, I, p. 777)

Antes de nada, señalaremos un hecho que hace tiempo notamos en Minima muerte y que también se da en los primeros libros de Prados: los versos "disfrazados». En efecto, "Y esto que marcha / conmigo", "y esto que va / tras de mí”, “y esta sombra / a la que sigo”, “¡a dónde va?: / ¿dónde voy?" (repárese en la falta de preposición en este último verso, propia del lenguaje popular), no son más que octosílabos disfrazados de versos más breves para la vista, no para el oído. Prados, salvo en su época surrealista, es poeta bastante refractario a alejarse de la métrica clásica; otras veces los versos son endecasílabos, fragmentados en sus componentes: $7+4$, y en este orden. Este poema, de estructura muy similar a la letrilla, es el segundo de los cuatro acogidos al título "Bajo la alameda”. En Dormido en la yerba desaparece; de la serie solo subsisten los números 1 y 4, aquel como 
"Nocturno", y este con el anterior título del conjunto: "Bajo la alameda" (pp. 31-32). La cuestión no es baladí, pero tampoco tenemos la clave para explicarla; solo nos fijaremos en la anomalía de que, en ese cuarto poemilla, a pesar del título general, no se habla de álamos sino de un ciprés. En los otros, no se mencionan árboles; sí un jardín en el primero, y hojas secas en el tercero. Al ańo siguiente, en la Antología, el único que se mantiene es el primero (p. 167), que recupera también el título mencionado, un título, como acabamos de ver, bastante elástico como para abrigar el primer poema, el cuarto o el grupo de los cuatro (además del poema XIX del segundo libro de $J C$ ). También el estribillo del cuarto (“¿Qué alto el ciprés! / ¿Qué alto el lucero!”) reaparece más adelante en el titulado “Otra vez” (p. 54), un caso más de ósmosis entre las células de ese organismo que es $J C$. Estamos, pues, ante un poema que no acabó de satisfacer a su autor, por la razón que sea. Prueba de ello es que en la segunda edición de $J C(=J C 2)$ sufre cambios de importancia:

Con temores voy

pero voy.

$\mathrm{Y}$ esto que marcha

conmigo;

y esto que va

5

tras de mí,

y esta sombra

a la que sigo

¡a dónde va?:

¿dónde voy?...

¿Con temores

vamos?

-Con temores.

(JC, 1960, p. 17)

El poemilla retocado tiene 13 versos en lugar de 12 . Se ha suprimido el v. 9 de la versión anterior, y se han ańadido los vv. 11-12, un interrogante cuyo verbo introduce la primera persona de plural. No es el único poema de JC que expresa miedo. El siguiente se titula "Temor de abril"; en el 14, 
"Copla”, leemos: "Algo me llama en la noche. / No sé qué es... / Algo en la noche me llama. / Miedo me da” (p. 59), y varios más de ese poemario insisten en el mismo concepto. Esa primera persona de plural (v. 12 de esta versión), poco frecuente en $J C$, contrasta con la primera de singular de vv. 1, 2, 8 y 9, y no acaba de convencer en poema tan centrado en el yo y su soledad (“¡el mundo es mi corazón!” dice en la p. 51, y algo más abajo: “-Yo, yo, yo... Soy yo, / yo. ¡Yo!”, para disipar toda duda), a menos que se entienda en su sentido impersonal, normal en castellano (por ejemplo, en la frase “¿Esas tenemos?”). Prados sabe sin duda lo que hace, pero, aparentemente, nos da un poema enmendado en 1960 como si fuese de 1946. JC2 no indica en ningún lugar que se trate de una versión corregida, ni tampoco aclara en su portada que se trate de una segunda edición, prosaicas minucias en las que Prados reparaba poco.

Veamos ahora un caso diferente, el de "Muerto en el sueño", $n^{\circ} \mathrm{X}$ de la primera parte del libro II (El dormido en la yerba, título aún usado en el poema XVI de este libro, p. 140, y recuperado en 1953 para la selección de $J C)$ :

\section{MUERTO EN EL SUEÑO}

Aquí estoy. ¡Junto al jazmín!

Si por mí preguntan, aquí estoy junto al jazmín.

Ay, amor, junto al jazmín:

arriba brilla el lucero,

sobre el agua su reflejo

y bajo el agua, mi sueño,

¡ay, amor!, junto al jazmín...

Amor: bajo el agua, muerto

junto al jazmín.

Amor, si por mí preguntan,

amor, sí, junto al jazmín:

¡toda la noche me oculta!

(JC, 1946, p. 130; PC, I, p. 851) 
El poema, aunque no se le aplique denominación formal, es una canción en el sentido juanramoniano que Prados empleará, posiblemente tomando como modelo las incluidas en Canción, libro publicado en 1936 por el poeta moguereño. Consta de trece versos, once octosílabos y dos más breves: el 2, hexasílabo, y el 10, pentasílabo. El grupo central (vv. 4-8) es incluso una clara reminiscencia del zéjel. La palabra-rima jazmín se repite seis veces, pero no hay versos sin asonancia: lucero / reflejo / sueño / muerto (vv. 5-7 y 9) es la segunda, mientras que la tercera, la de preguntan (v. 2), se recoge en el v. 11 y remata el poema (v. 13, oculta). Se plantea así una oposición en los tres primeros versos, donde la asonancia $u$-a (preguntan) cede a la dominante -ín, propia del término más frecuente y destacado: jazmin. Un dominio que al final se invierte, puesto que los cinco versos últimos, sin perder de vista al jazmín, lo dejan en segundo lugar: "Amor, si por mí preguntan, / amor, sí, junto al jazmín: / ¡toda la noche me oculta!" (vv. 11-13). La admiración del verso resalta su importancia. No pretendemos interpretar el sentido profundo del poema ni de ninguno de sus versos. Nos limitamos a estudiar su prosodia, incluso su disposición gráfica, y naturalmente su sintaxis y sentido literal. El poeta subraya el hecho de estar oculto, aunque el lector sepa ya que él, o quizá su sueño (v. 7), está muerto, bajo el agua (v. 9), y junto al jazmín. Pero esta frase, repetida seis veces casi como si fuera un estribillo, no deja de ser un complemento circunstancial, un rema, si queremos usar del tecnicismo, frente al tema, que se reparte entre el verso inicial y el final: "Aquí estoy... / ¡toda la noche me oculta!" (vv. 1 y 13).

El poema se reproduce tal cual en Dormido en la yerba (1953), pp. 75-76. Pero en la Antología de 1954 (p. 188) presenta dos variantes; la primera es, obviamente, un desliz en la composición material: el blanco entre vv. 3-4 aparece aquí entre vv. 4-5, a pesar de que el v. 5 empieza con minúscula. La segunda es la que nos interesa: el poeta añade un octosílabo al final del poema, uno de esos versos prosódicamente contradictorios, puesto que lleva a la vez admiraciones y paréntesis, es decir, forte pero piano, como si dijéramos una admiración en voz baja: “(¡Noche soy, para vivir!)". Lo que sorprende, en el añadido, es que cambia el turno tal como lo establecimos antes, y hace ganar la competición a la rima de jazmín, con la asonancia aguda de vivir. Si el v. 13 decía: la noche me oculta, y así terminaba el poema en su primera versión, ahora el 14 precisa más 
el concepto, ampliándolo: noche soy, para vivir. La canción, sin dejar de serlo, adopta un final de romance en sus seis últimos versos (9-14), con la asonancia $-i$ en los alternos $(10,12$ y 14), y termina con un toque algo más esperanzado, en que el poeta se explica a sí mismo la razón de ser de su ocultación, de su vivir al margen.

Podríamos creer que el texto ha cambiado de carácter, ha encontrado su forma definitiva. Pero Prados, poco después de publicada esa Antología por la que fue algo menos desconocido en Espańa e Hispanoamérica, se puso a preparar su gran Selección de 1959, que quedó inédita, y la segunda edición de Jardín cerrado impresa al año siguiente. El poema del que hablamos figura en su p. 63, y, sorprendentemente, recupera la forma que ostentaba en la primera edición, con solo 13 versos. El ańadido en la Antología ha desaparecido. ¿Por qué? No lo sabemos. Sospechamos que Prados, para esa segunda edición, hubo de enviar a Buenos Aires un ejemplar de la primera, con algunas alteraciones manuscritas, pero olvidando el cambio introducido en la versión de la Antología. ¿Olvidándolo o anulándolo? He ahí una cuestión que no podemos responder.

Si el poema anterior sufrió el efímero añadido de un verso, ahora vamos a examinar el caso contrario, en el que un poema lo pierde. Se trata de una canción perteneciente al libro tercero de $J C$, titulado Umbrales de sombra: meditaciones, coplas, insomnios y presentimientos al margen de un jardin, cuya tercera parte, Constante amigo, contiene trece poemas, de los cuales este es el segundo:

\section{CANCIÓN}

Una vez tuve una sangre que sońaba en ser un río. Luego, soñando y soñando, mi sangre labró un camino.

Sin saber que caminaba,

mi sangre comenzó a andar, y andando, piedra tras piedra, mi sangre llegó a la mar.

Desde la mar subió al cielo... Del cielo volvió a bajar 
y otra vez se entró en mi pecho

para hacerse manantial

y agua de mi pensamiento...

Ahora, mi sangre es mi sueño

y es mi sueńo, mi cantar,

$y$, mi cantar, es eterno.

$$
\text { (JC, 1946, p. 309; PC, I, p. 990) }
$$

El poema consta de 16 versos octosílabos repartidos en tres grupos de 4, 9 y 3, con variedad de asonancias en unos, sueltos los otros, como aquí sucede con los versos 1, 3, 5 y 7 . En cuanto a la rima, se divide en dos partes: la primera mitad (vv. 1-8) contiene dos asonancias, $-i-o /-a ́$, que abarcan versos alternos, mientras que la segunda mitad (vv. 9-16), que conserva la segunda asonancia, no deja versos sueltos, sino que les intercala otros con asonancia nueva en -é-o. Esta rara disposición subraya la progresión del contenido: al principio, la sangre sueńa, se hace camino, anda sin saber, hasta que llega al mar, algo expresado por la alternancia entre versos asonantados y sueltos. Luego todo se hace más concreto, menos divagatorio, y las asonancias se encargan de marcarlo, hasta que las cosas se definen con tres oraciones copulativas en anadiplosis: «mi sangre es mi sueño, / ... es mi sueńo mi cantar, / y, mi cantar, es eterno», donde los tres verbos suenan como martillazos. La nueva asonancia -é-o se impone y subraya los términos más marcados: cielo... pecho... pensamiento... sueño... eterno.

Este poema no fue recogido en Dormido en la yerba, pero en JC2, p. 152, carece del v. 13 (y agua de mi pensamiento...), de forma que la rima dominante en el segundo grupo de versos es ahora la asonancia aguda $-a ́$, y solo en el último se impone la asonancia -é-o. El poeta reparte las rimas por los grupos de distinta manera; así el segundo, en lugar de terminar en una cuarteta, como antes hacía, termina en un tercetillo, anunciando el que remata el poema. Para mantener las mismas asonancias alternas durante seis versos se ha sacrificado el 13 ( $y$ agua de mi pensamiento...), que en realidad poco añadía a los dos precedentes ( $y$ otra vez se entró en mi pecho / para hacerse manantial). Semejante operación no parece debida al azar, sino a la constante labor de lima a la que Prados somete su poesía. 
Esta en concreto nos muestra el paso desde el desconcierto hasta la seguridad. El poeta recuerda haber estado perdido, pero al fin ha encontrado su camino, y tanto las palabras como los juegos de rimas que poco a poco se van afianzando no hacen más que confirmarlo.

Ahora bien, si se examina con cuidado la edición de 1960 destacan en ella un par de anomalías: la distribución de los 16 versos en tres grupos desaparece porque ahora van seguidos, con interlineados iguales. Y el v. 12 (para hacerse manantial) no concluye con puntuación, a pesar de que el siguiente (Ahora, mi sangre es mi sueño) comienza con mayúscula. Si Prados hubiese decidido suprimir el v. 13 (y agua de mi pensamiento...), tal como pensábamos, lo lógico sería marcar tal supresión poniendo punto tras el v. 12. Pero no lo hizo. ¿Qué debemos pensar entonces los lectores? ¿Estamos ante una versión revisada del poema, que sin duda gana al eliminarse ese v. 13, o simplemente ante una omisión debida a la casualidad, y al descuido con que Prados, según todos los testimonios, corregía pruebas de los libros que tenía entre manos?

La Antología fue, como se sabe, pieza importante en la producción de Prados, la que más lo dio a conocer, y también la primera obra que le publicaría la editorial Losada; un libro que el poeta preparó con cuidado, y del que se supone que corrigió pruebas con más esmero del habitual. Pues bien; por poner solo algún ejemplo de lo relativo que es tal esmero, en El misterio del agua (1927), el "milagro" tercero, aunque numera con I su primera parte (p. 44), omite la segunda, que los editores de Prados repusimos ya en 1975 a partir de los manuscritos. En la sección Constante amigo, de $J C$, a la que también pertenece el último poema estudiado, la canción "Una cosa es estar muerto" (p. 229), en lugar de los 14 versos que presenta en la primera edición (p. 316), en la Antología tiene 15, porque repite el v. 11 entre el primero y el segundo, lo que estropea la secuencia de tercetillos. No obstante, la Antología recupera la lectura correcta llámeme del v. 13, que ya estaba bien en Memoria del olvido (México: Séneca, 1940, p. 135) y se había estragado en la primera edición de JC. Si pasamos al siguiente libro, Río natural, fechado en 1953 e impreso también por Losada en 1957, su primer poema, "Sangre de Abel", omite el segundo verso en la Antología, dejando inconclusa la frase que lo abre: "Cantando estoy llenando" (falta el complemento directo: "mis huecos en la muerte", p. 261). A esto se suma que buena parte de los poemas 
de su primera época van lastrados por versos añadidos palmariamente en México 20 o 30 años más tarde, como sucede en pp. 13, 16, 18, 20, 21, 23 y 26, lo que falsea su sentido original. Dejando ahora la Antología, en $P C$, II, p. 395, tuvimos ocasión de señalar y reponer un verso omitido en el poema "Año nuevo", perteneciente a la cuarta parte (Cambios de estado) de La piedra escrita (México: UNAM, 1961), último libro del que el malagueño pudo ver pruebas, lo cual indica que en este tipo de poesía la falta o sobra de un verso no siempre se nota en la simple lectura.

En JC2 hizo Prados otras maniobras que pueden pasar por enmiendas: aparte los casos estudiados, en el libro segundo (El dormido en la yerba), el poema "El pecho y la luna" pierde tres de sus versos, bien es verdad que ya habían aparecido antes (1946, p. 123; 1960, p. 60). En el tercer libro (Umbrales de sombra), el poema "La rosa en la mano" (1946, p. 199; 1960, p. 95) omite el v. 11, pero eso ya suena más a descuido. Lo mismo cabe decir del innecesario verso inserto después del 10 en el "Cantar sonámbulo", del libro cuarto (La sangre abierta; 1946, p. 351; 1960 , p. 177), mientras que ha de ser intencional hacer interrogativo el último verso del poema VII, 4 de ese mismo libro ("El cuerpo ante el espejo"; 1946, p. 404; 1960, p. 204), a lo cual hay que agregar supresión de títulos, reorganización del cuarto libro y cierto número de erratas. Con todo ello, y sin menoscabo de su talla poética, se puede decir que Prados, para un filólogo, es poco de fiar, y no serviría de mucho husmear en sus manuscritos; la única vía, y no del todo segura, sería encontrar las galeradas de sus obras impresas, a fin de vislumbrar con qué criterio fueron corregidas.

Terminaremos con un ejemplo tomado del poema final de $J C$, que en la en la edición de 1946 carece de epígrafe y ocupa solo la cuarta parte (El cuerpo en el alba) del libro cuarto (La sangre abierta). Decíamos que también la estructura de ese cuarto libro sufrió cambios en JC2: en lugar de las cuatro partes que ostenta en la primera edición, la segunda distribuye sus poemas en solo tres, habiéndose suprimido el título de la tercera (El germen que se cumple); pero el texto de JC2 no se corresponde con el índice del volumen. En efecto, el poema en cuestión lleva un 3, cosa extraña porque el precedente va numerado como 5 (p. 204). El índice aclara lo sucedido: el poema, ahora titulado "El cuerpo en el alba", debería ocupar, él solo, la Tercera parte homónima (El cuerpo en el alba), igual 
que había ocupado la Cuarta en la edición anterior, y a ello alude el 3 de la numeración. El tipógrafo no entendió bien la enmienda, y el poeta no vio el fallo del tipógrafo ni la discrepancia entre índice y texto. Es obvio que deseaba mantener aislado un buen poema conclusivo, que arranca en tono solemne: "Ahora sí que ya os miro / cielo, tierra, sol, piedra, / como si al contemplaros / viera mi propia carne" (p. 407), y que termina con mayor énfasis, no lejos de Hölderlin:

\author{
Ya soy Todo: Unidad \\ de un cuerpo verdadero. \\ De este cuerpo que Dios llamó su cuerpo \\ y hoy empieza a sentirse \\ ya, sin muerte ni vida, \\ como rosa en presencia constante \\ de su verbo acabado y, en olvido \\ de lo que antes pensó aun sin llamarlo \\ y temió ser: Demonio de la Nada.
}

(JC, p. 409; PC, I, pp. 1069-1070)

Prescindamos de su peregrina puntuación. Juan Larrea, hombre cuidadoso, al prologar la edición de 1946, habrá manejado el mecanoscrito del poeta, y cita estos versos con una curiosa variante: “... y temió ser: Dominio de la Nada" (p. 16; PC, I, p. 756). El Demonio se ha convertido en Dominio; Prados no lo advirtió, y, aunque la lectura aparezca corregida en los manuscritos, nos queda la duda de qué término figuraría en su original. Como acabamos de ver, en esta poesía el buen sentido del lector no siempre ayuda a salvar las erratas, incluso cabe sospechar que alguna pudo parecerle bien a su autor y la dejó pasar. Al menos aquí, en medio de la Nada, el dominio y el demonio tampoco son tan diferentes.

Bibliografía

Blanco Aguinaga, Carlos, Lista de los papeles de Emilio Prados, Baltimore, Md: The Johns Hopkins Press, 1967. 
Carreira, Antonio, «La construcción del libro y del poema en Emilio Prados", AA. VV., Emilio Prados: un hombre, un universo, Málaga, Centro Cultural de la Generación del 27, 2000, pp. 167-186.

- «La poesía órfica en Minima muerte de Emilio Prados», en AA. VV., Los refugiados españoles y la cultura mexicana. Actas de las terceras jornadas (dedicadas a Emilio Prados), Madrid, Residencia de Estudiantes / El Colegio de México, 2002, pp. 109-126.

Jiménez, Juan Ramón, Canción, Madrid, Signo, 1936.

Prados, Emilio, Memoria del olvido, México DF, Séneca, 1940.

- Jardín cerrado, México DF, Cuadernos Americanos, 1946; prólogo de Juan Larrea. 2a ed., Buenos Aires, Losada, 1960.

- Dormido en la yerba, Málaga, El Arroyo de los Ángeles, 1953.

- Antología (1923-1953), Buenos Aires, Losada, 1954.

- Río natural, Buenos Aires, Losada, 1957.

- Poesías completas, ed. Carlos Blanco Aguinaga y Antonio Carreira, México DF, Aguilar, 1975-1976, 2 vols.

- Poesias completas, ed. Carlos Blanco Aguinaga y Antonio Carreira, Madrid, Visor, 1999, 2 vols. 